\title{
An efficient stress-free strategy to displace stable bacterial plasmids
}

\author{
Lisa Hale*, Orestis Lazos**, Anthony S. Haines, and Christopher M. Thomas \\ School of Biosciences, University of Birmingham, Edgbaston, Birmingham, UK \\ BioTechniques 48:223-228 (March 2010) doi 10.2144/000113366 \\ Keywords: plasmid curing; replication; post-segregational killing; mobile genetic elements; antibiotic resistance; virulence \\ Supplementary material for this article is available at www.BioTechniques.com/article/113366. \\ ${ }^{*}$ L.H.'s current address is the School of Life Sciences, Oxford Brookes University, Gipsy Lane, Headington, Oxford OX3 0BP, UK. \\ ${ }^{* *}$ O.L.'s current address is the Department of Biochemistry, University of Cambridge, Tennis Court Road, Cambridge CB2 1QW, UK.
}

A key stage in determining the phenotype(s) conferred by a plasmid is its displacement, or 'curing,' to create a plasmidfree strain. However, many plasmids are very stable, not only because they contain multiple replicons, but also because they can encode post-segregational killing systems that reduce the viability of plasmid-free segregants. We have developed an efficient curing strategy that involves combining key regions of the replicons and the post-segregational killing loci into an unstable cloning vector carrying $s a c B$, which confers sensitivity to sucrose. Targeting plasmids of both the F family of Escherichia coli and the broad-host-range IncP-1 family, we demonstrated displacement of susceptible resident plasmids from all clones tested. Growth on sucrose allowed the isolation of many clones without either plasmid. This strategy is highly efficient and avoids the stress of inducing and surviving the effects of post-segregational killing systems or other lethal gene products.

\section{Introduction}

Many bacteria carry a variety of mobile genetic elements that can contribute significantly to their diversity and adaptability (1). Although current DNA sequence databases allow predictions about function based on bioinformatics, it is still important to experimentally test the contribution of plasmids to the phenotype of their host. To do this, one must (i) obtain a plasmidfree segregant that has lost the plasmid and determine what properties have changed, and (ii) transfer the plasmid to a new strain and determine what new phenotype(s) is acquired (2). Important for this empirical work is the displacement of the plasmid from its host, a process called curing. While some plasmids are naturally unstable, many are very persistent and active curing strategies are needed to obtain plasmid-free bacteria.

The classic strategy to cure a strain of its resident plasmid is to stress the host bacteria in some way, such as by growth at high temperatures or in the presence of detergent, mutagens, or other DNA-modulating agents (2). Unfortunately this may also favor mutation of the chromosome irrespective of whether the plasmid has been displaced, thereby seriously undermining any conclusions (although this issue does not seem to have been systematically investigated). Alternatively, plasmid incompatibility-arising when two plasmids carry related replication or stable inheritance functions-can be used to displace the resident plasmid (3). Displacement can be unidirectional if one of the two plasmids contains a second unrelated replicon, especially if it has a naturally higher copy number (4). If plasmid elements (e.g., copy number regulators or replication origins) are cloned into a compatible vector, they can block replication of the endogenous plasmid. This is a powerful approach that is also the basis of a general plasmid classification system (5).

However, a major barrier to curing is that many plasmids encode what are called post-segregational killing systems (PSKs) (6). Killing of plasmid-free segregants happens because the plasmid leaves behind a toxin that becomes active after loss of the plasmid. Known systems encode either a slowly activated mRNA which encodes a toxin, or a protein toxin itself. Production of active toxin is prevented while the plasmid is present, either by regulation of translation of the toxin-encoding mRNA with antisense RNA or by antidote proteins. In both cases, the regulator or antidote is unstable and so rapidly disappears once the plasmid that encodes them is no longer present. If the bacteria survive loss of the plasmid, they may have an increased chance of carrying mutations because some PSKs target DNA gyrase $(7,8)$ - inducing the SOS response-causing elevated errorprone repair and mutation rate. Therefore, to improve a plasmid displacement strategy based on incompatibility, we proposed that the curing vector should be supplemented with the plasmid's PSK system's antitoxins or anti-sense RNA genes. This point does not seem to have been generally recognized in the design of plasmid displacement strategies to date, although while this manuscript was being prepared, a paper that implicitly covers this point with respect to the Agrobacterium tumefaciens Ti plasmid was published (9).

Using this principle, we devised a general strategy to achieve efficient plasmid displacement and apply it to displace F-like and IncP-1 plasmids from their hosts. pO157 is a typical F-like plasmid, possessing 
multiple replicons and stable inheritance functions $(10,11)$. Previously pO157-free strains have been obtained by incompatibility with a mini-replicon derived from just part of the $\mathrm{pO} 157$ genome, but curing was only successful in a proportion of the transformants (12). By contrast, our approach results in highly efficient displacement and can be extended to other F-like plasmids. We have also developed a similar strategy to cure IncP-1 plasmids $(13,14)$ demonstrating the general applicability of this strategy to other groups of plasmids.

\section{Materials and methods}

Bacterial strain, plasmids, and growth conditions

E. coli K12 strains used were $\mathrm{DH} 5 \alpha(15)$, S17-1 (16), NEM259 (17), and JM109 (18). E. coli O157:H7 Sakai strain stx- (toxin deficient) (12) was used to reduce health risks. Plasmids used or constructed during this work are listed in Supplementary Table S1. The standard medium was Luria Bertani (LB) broth, or L-agar (LB solidified with $1.5 \% \mathrm{w} / \mathrm{v}$ agar) and growth was at $37^{\circ} \mathrm{C}$. Antibiotics used were kanamycin, $50 \mu \mathrm{g} /$ $\mathrm{mL}$; penicillin, $150 \mu \mathrm{g} / \mathrm{mL}$ (broth) or 300 $\mu \mathrm{g} / \mathrm{mL}$ (agar); streptomycin, $30 \mu \mathrm{g} / \mathrm{mL}$; and trimethoprim, $100 \mu \mathrm{g} / \mathrm{mL}$.

DNA isolation, manipulation,

and sequencing

Small-scale purification of plasmid DNA used a modified Birnboim and Doly procedure (19). PCR products for sequencing or further study were cloned using the Promega pGEM-T Easy vector system. Agarose gels were run in TAE (20). DNA sequencing was carried out using the Big dye terminating kit manufactured by PE-ABI, which is based on the chain termination method (21). The sequencing reactions were run on an $\mathrm{ABI} 3700 \mathrm{DNA}$ sequencer (Functional Genomics Lab, University of Birmingham, Edgbaston, UK).

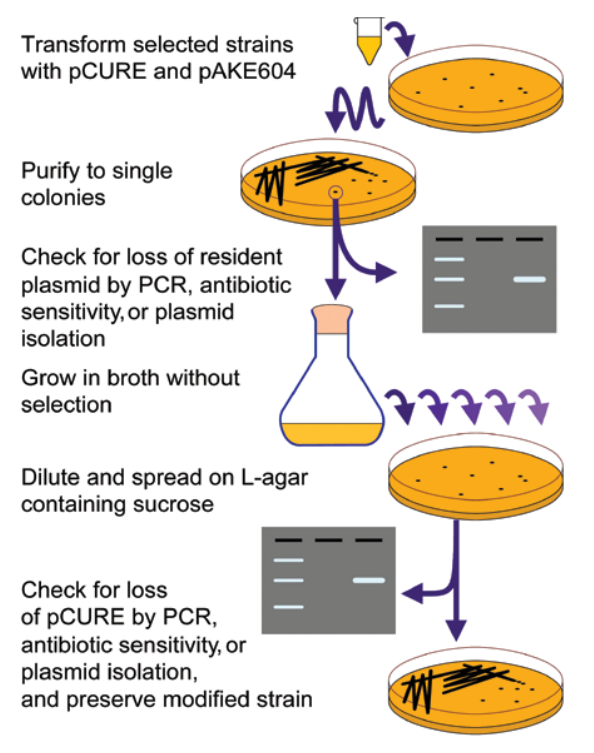

Figure 1. Summary of the general pCURE plasmid curing procedure. Starting from a strain that carries a plasmid to be displaced the pCURE plasmid is introduced by transformation or conjugation. After purifying the bacteria carrying the pCURE plasmid, displacement of the resident is checked by phenotypic screening or DNA isolation and gel electrophoresis. Finally, loss of the pCURE plasmid is selected by growth on sucrose and confirmed by screening of plasmid DNA.

\section{PCR}

PCR reactions were performed by standard protocols (22). Primers (Alta Bioscience, University of Birmingham) were designed to flank the region of interest with extra restriction sites for cloning if needed (Supplementary Table S2). The DNA polymerases used were Expand High Fidelity system (Cat. no. 03033242001; Roche, Mannheim, Germany) for gene cloning and Taq DNA polymerase (Cat. no. 18038026; Invitrogen, Carlsbad, CA, USA) for confirmation of chromosomal genotype. Glycerol was also added to the diagnostic
PCR reactions to a final concentration of $5 \%$. PCR products were purified using a HIGH Pure PCR Cleanup kit (Cat. no. 04983955001; Roche). Standard PCR conditions were as follows: denaturation at $94^{\circ} \mathrm{C}$ for $4 \mathrm{~min} ; 10$ cycles of denaturation at $94^{\circ} \mathrm{C}$ for $30 \mathrm{~s}$, annealing at $59^{\circ} \mathrm{C}$ for $30 \mathrm{~s}$, annealing at $57^{\circ} \mathrm{C}$ for $15 \mathrm{~s}$, and extension at $72^{\circ} \mathrm{C}$ for $90 \mathrm{~s} ; 20$ cycles of denaturation at $94^{\circ} \mathrm{C}$ for $30 \mathrm{~s}$, annealing at $59^{\circ} \mathrm{C}$ for $30 \mathrm{~s}$, annealing at $57^{\circ} \mathrm{C}$ for $15 \mathrm{~s}$, and extension at $72^{\circ} \mathrm{C}$ for $90 \mathrm{~s}$ with an increment of $5 \mathrm{~s}$ every cycle; and final extension at $72^{\circ} \mathrm{C}$ for $7 \mathrm{~min}$.

\section{General design and construction of} pCURE plasmids

The core system uses a plasmid vector that is lost at low frequency in the absence of selection. We used pAKE604 (23) based on the pMB1 replicon from pEX100T (24). It can be introduced by transformation or mobilized by the IncP-1 transfer system in strain $\$ 17-1$ due to inserted ori $T_{\mathrm{RK} 2}$ and is selected by resistance to kanamycin or ampicillin. The plasmid also carries sacB encoding levan sucrase that polymerizes fructose from sucrose onto a sucrose starter unit in the periplasm: this causes Gram-negative bacteria to become sensitive to sucrose and allows plasmid-free segregants to be isolated easily (25). The functionality of $s a c B$, as indicated by sensitivity to sucrose, must be checked regularly by spreading bacteria with the plasmid on agar with kanamycin and $5 \%(\mathrm{w} / \mathrm{v})$ sucrose.

To create pCURE plasmids, replication and stable inheritance functions were identified in the target plasmid by BLAST searches and elements expected to interfere with their function were chosen. For replication, this involved either repression of a vital component of the system (e.g., a transcriptional repressor, an antisense RNA, or other translational regulator) or competition for a vital step

Table 1. Genetic loci included in pCURE1 and pCURE2

\begin{tabular}{|c|c|c|c|c|c|c|}
\hline \multirow{2}{*}{ Locus } & \multicolumn{6}{|c|}{ Coordinates $^{a}$} \\
\hline & p0157 & p1685/97 & pKDSC50 & $\mathbf{F}$ & pCURE1 & pCURE2 \\
\hline repFIA (incC) & & & & $49,141-49,476$ & & 7410-7735 \\
\hline repFIB & $48,289-49,890$ & & & & 4337-5937 & $4950-6550$ \\
\hline repFIC (copAB) & 2351-3053 & & & & 5937-6797 & $6550-7410$ \\
\hline repFIC/FIIA (copAB) & & & $24,300-25,062$ & & & $7735-8435$ \\
\hline$f \operatorname{lm} B($ sok $)$ & $73,732-73,988$ & & & & $3582-3852$ & $3582-3852$ \\
\hline $\operatorname{let} A(\operatorname{ccd} A)$ & $51,692-52,170$ & & & & $3852-4337$ & $3852-4337$ \\
\hline peml & & $40,448-40,857$ & & & & $4337-4737$ \\
\hline srnC (sok) & & $124,504-124,270$ & & & & $4737-4950$ \\
\hline
\end{tabular}

aFor p0157, p1685/97, pKDSC50, and F, the coordinates correspond to the coordinates in the annotated sequence from GenBank that defines the end of complementarity to the primers used for PCR. For pCURE1 and pCURE2, the coordinates correspond to the middle of the restriction sites that define the ends of the segments joined by ligation and inserted into pAKE604. 


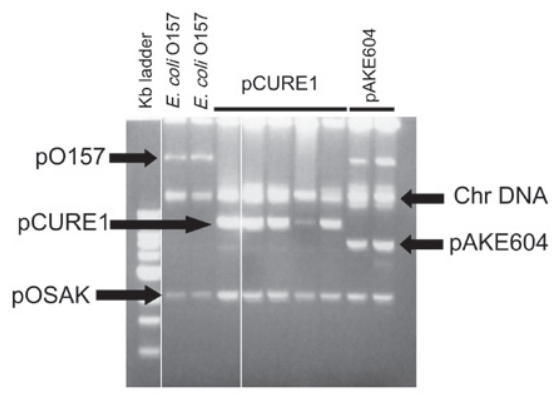

Figure 2. Visualization of p0157 displacement by pCURE1. Agarose gel electrophoresis of plasmid DNA extracts showing loss of p0157 when pCURE1, but not pAKE604, is introduced. Plasmid pOSAK is the small resident plasmid that is also present in E. coli 0157.

in the process (e.g., a replication origin). For PSK systems, we chose the putative antidote protein for proteic systems or the region encoding any repressor antisense RNA for non-proteic systems. PCR primers were designed to amplify one or more of each key element to increase the chance of functioning against divergent but related systems. Careful choice of restrictions sites allowed the products to be joined without regenerating the sites. The PCR products were cloned into the vector $\mathrm{pGEM-T} \mathrm{Easy} \mathrm{and} \mathrm{the} \mathrm{sequence}$ validated before insertion into pAKE604. This created multifunctional DNA tracts relatively devoid of restriction sites.

Standard plasmid curing experiment The general strategy is outlined in Figure 1. The pCURE plasmid was introduced into a chosen strain either by transformation of competent bacteria or by conjugative transfer from the $E$. coli strain S17-1 and selected on agar that prevents growth of the donor bacteria but also contains kanamycin to select the pCURE plasmid. Transformants or transconjugants were purified to single colonies on selective agar and then checked for the presence of the resident plasmid either on the basis of selectable markers (normally 25 colonies were replica-plated), plasmid DNA preparations (normally 12 cultures were analyzed), or by PCR amplification of a plasmid region (normally DNA extracts of two strains were checked). Assuming successful displacement, a purified clone that demonstrated sensitivity to sucrose was then grown without selection. Segregants that had lost the pCURE plasmid were then selected by growth on L-agar plus sucrose without antibiotic. Sucrose-resistant colonies were checked for the absence of the pCURE plasmid by checking loss of antibiotic resistance (normally 25 colonies were replica-plated), as well as by disappearance of the plasmid band in DNA extracts (normally 12 cultures were analyzed).

\section{Results and discussion}

Design and construction of pCURE1 to displace pO157

The first displacement plasmid produced, pCURE1, was designed to displace pO157 from its host E. coli O157:H7. This served as a useful test of our proposed strategy because pO157 contains multiple replicons and PSK systems representative of $\mathrm{F}$ incompatibility group plasmids $(10,11)$ : two replicons-repFIIA (26) and repFIB (27) - and two post-segregational killing systems, designated $c c d A B$ (let $A B)(28)$ and parB (hok/sok) $(29,30)$ (Table 1). To block replication, we chose the antisense RNA, CopA, that indirectly blocks translation of the repFIIA rep gene (31) and the combination of the FIB rep gene and associated iterons (Rep protein binding sites) which both combine to give the control of replication (32). To block the PSK systems, we chose the control/ antidote regions from the identified postsegregational killing systems (sok of the $h o k / s o k$ system and let $A$ from the let $A B$ system). Primers were designed to amplify each of these loci, PCR was performed, the products cloned, their sequences checked, and then sequentially joined together and inserted into pAKE604 (as described in the "Materials and methods" section) to give pCURE1.

Sucrose sensitivity conferred on E. coli $\mathrm{DH} 5 \alpha$ by pCURE1 was checked as described in the "Materials and methods" section. Starting from a single sucrosesensitive colony of DH5 $\alpha$ (pCURE1), we then checked that sucrose-resistant bacteria had lost the plasmid. After growth with selection, $0.04 \%$ of the population was sucrose-resistant; in the absence of selection, this rose to $0.13 \%$. Plasmid loss was confirmed in all sucroseresistant colonies tested, first by loss of kanamycin resistance and second by plasmid DNA extraction and gel electro- phoresis. These results confirmed that pCURE1 confers sucrose sensitivity and that segregants that have lost pCURE1 can be selected with sucrose.

Validation of the curing capacity of pCURE1

E. coli O157:H7 stx ${ }^{-}$was transformed separately with pCURE1 or pAKE604, its parent vector. No difference in the transformation frequency or colony size by the two plasmids was detected indicating no activation of the PSK systems. Transformants were purified by two rounds of streaking to single colonies on agar, selecting for pCURE1. Plasmid DNA isolation from randomly selected clones showed that the $\mathrm{pO} 157$ bands disappeared in the presence of pCURE1 but remained with pAKE604 (Figure 2). Overnight growth without kanamycin and then selection for sucrose resistance resulted in loss of both pCURE1 and pAKE604. Using PCR with pO157-specific primers, we confirmed that pO157 had not integrated into the chromosome as a result of curing by pCURE1. These data therefore demonstrate that the genetic determinants chosen for inclusion in pCURE1 are sufficient to achieve efficient displacement of pO157.

Construction of pCURE2 to displace a wider range of $\mathrm{F}$-like plasmids To extend the usefulness of pCURE1 to cure a more diverse range of the $F$ incompatibility group plasmids, we designed pCURE2 after performing BLAST searches with representative plasmids from the FI, FII, FI/II incompatibility groups. Replicons or PSK systems not present in pCURE1, or those that had identities of $<80 \%$ to those in $\mathrm{pO} 157$, were identified and a representative selection of loci were amplified and cloned into pCURE1. The additional genetic loci chosen were $\operatorname{srnB} / \operatorname{srn} C$ from p1658/97 (33) (the coding region for antisense RNA srn $C$ was amplified) and pemI/per $K$ from p1658/97 (33) (the coding region for the PemI anti-toxin protein was amplified) for PSK systems; and RepFIA from F (the

Table 2. Genetic loci included in pCURE11

\begin{tabular}{|c|c|c|}
\hline \multirow{2}{*}{ Locus } & \multicolumn{2}{|c|}{ Coordinatesa } \\
\hline & RK2 & pCURE11 \\
\hline oriv & $12,366-12,992$ & $5200-5828$ \\
\hline $\operatorname{parD}$ & $35,029-35,395$ & 3589-3955 \\
\hline korA-incC & $58,239-59,466$ & $3955-5200$ \\
\hline
\end{tabular}


Literally stacked

\section{with new features}

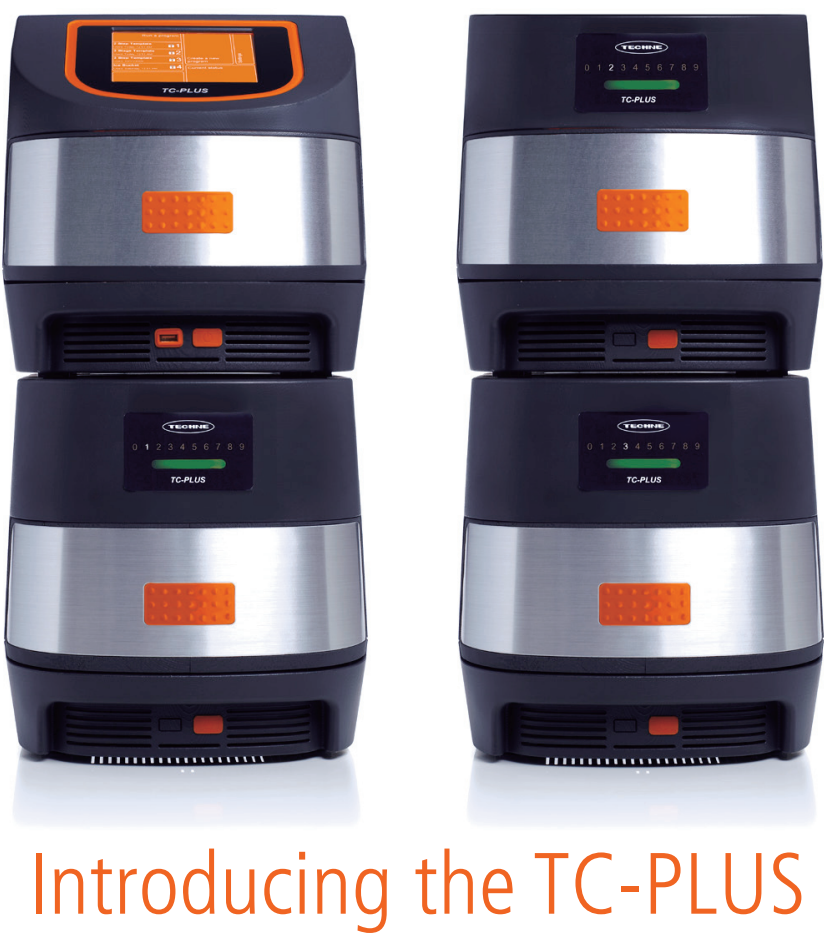

Multi-format Thermal Cyclers

The TC-PLUS thermal cyclers have all the latest features from a colour touchscreen to fast ramp rates along with some innovative additions such as an automatic, non-motorised heated lid (patent pending), environmentally friendly TERS $^{\text {TM }}$, thermal energy recovery system (patent pending) to reduce operating costs and a unique space-saving, stackable design.

The TC-PLUS and Satellite units can be combined to form any multi-block format with the Satellites being controllable from either a PC or the TC-PLUS.

* 4-year warranty with blocks having a 4-year or 100,000 cycle warranty - whichever comes first.

Purchase of this instrument conveys a limited non-transferable immunity from suit for the purchaser's own internal research and development and applied fields other than human in vitro diagnostics under non-real time thermal cycler patents of Applied Biosystems LLC.
- Colour touchscreen for fast program setup

- TERS $^{\mathrm{TM}}$, Thermal Energy Recovery System (patent pending) to reduce operational costs

- Stackable design to save on valuable bench space!

- Satellite option which can be controlled by either the TC-PLUS or a PC

- Unique, easy to use CD-type sample drawer mechanism (patent pending) which provides the correct pressure for use with caps: domed or flat, heat OR adhesive seals all without the use of a motor!

- Tm calculator, which uses the Nearest Neighbour algorithm

- Fast ramp rate of up to $5^{\circ} \mathrm{C} / \mathrm{sec}$

- 4-year warranty* complete sequence of $\mathrm{F}$ is not yet published but is available as NCBI sequence accession no. NC 002483) and RepFIIA from pKDSC50 (34) for replication systems. The inc $C$ region of $F$ repFIA replicon contains five direct repeats that bind RepE, the replication initiator protein, and is involved in copy number control and incompatibility (35). As described for pCURE1 above, the repFIIA replicon is regulated by repressor CopB and antisense RNA CopA. The extra four loci were spliced into pCURE1 as described in the "Materials and methods" section. The result was a plasmid (Table 1) that should have been capable of displacing a wider range of F-like plasmids.

This second-generation plasmid, pCURE2, was tested for its ability to displace additional IncF plasmids. We first tested it against pKDSC50, which is similar to $\mathrm{pO} 157$ in having just two replicons (RepFIB and RepFIIA), but carries a divergent FIIA replicon. The results confirmed that pCURE2 displaces pKDSC 50 from all tested clones. A more stringent test was to use it against a derivative of $\mathrm{F}$ itself that contains three replicons. For this we chose the $\mathrm{F}^{\prime}$ plasmid carrying the pro $A B$ lac $Z \Delta$ chromosomal segment that is present extensively in standard E. coli laboratory strains; we chose JM109 for this purpose. Neither pAKE604 nor pCURE1 could displace the $\mathrm{F}^{\prime}$, with all transformants tested (at least 20) retaining the ability to complement the auxotrophic defect in JM109. However, introduction of pCURE2 resulted in an inability to grow on minimal medium due to the loss of the pro $A B$ genes carried on the $\mathrm{F}^{\prime}$. This confirms that the extra genes in pCURE2 make it more effective than pCURE1 in displacing complex F plasmids.

\section{Design and construction of pCURE11}

to displace IncP-1 plasmids

To show that this strategy can be applied to other plasmid groups, we constructed a pCURE plasmid for the IncP-1 group. The replication origin (oriV), as well as parD, $\operatorname{kor} A$, and inc $C$ genes were amplified from the IncP-1 $\alpha$ plasmid RK2 (13) using PCR and cloned into pAKE604 to form pCURE11 (Table 2). For ori $V$, the chosen region included its nine iterons, which should titrate TrfA replication initiator protein away from oriV (36) and possibly actively block its function through handcuffing that limits access to host proteins (37). ParD is an anti-toxin to a post-segregational killing system and autogenously regulates a two-gene operon (38). KorA and IncC are encoded by the central control region (ccr) and are concerned with repression (39) and active partitioning respectively (40). The KorA regulon includes-and repressesthe $\operatorname{trf} A$ operon, which is essential for replication (41), while IncC produced in trans is known to destabilize RK2(42). These regions were amplified by PCR and cloned into pAKE604 as described in the "Materials and methods" section.

\section{Validation of pCURE11 curing properties}

The ability of pCURE11 to displace IncP- $1 \alpha$ plasmids from their host was tested using pRK24, a derivative of RK2 that does not confer kanamycin resistance (43). Displacement of pRK24, identified by screening for loss of tetracycline resistance, occurred in all transformants tested with pCURE11, but none of pAKE604 transformants. Curing of the IncP- $1 \alpha$ plasmid by pCURE11 was further verified by extraction of plasmid DNA and gel electrophoresis. The pCURE11 transformants were sucrosesensitive, as expected, and sucrose-resistant derivatives had lost pCURE11 as indicated by both kanamycin sensitivity and DNA profile. Thus pCURE11 can cure an IncP-1 plasmid from E. coli and pCURE11-free segregants can then be selected by growth in the presence of sucrose. 
Since the IncP-1 plasmids consist of a number of subgroups, the ability of pCURE11 to displace IncP1- $\beta$ plasmids from their host was investigated using IncP1- $\beta$ plasmid R751 (14). After transformation of $E$. coli NEM259[R751], loss of trimethoprim resistance indicated displacement of R751 by pCURE11 but not pAKE604; this conclusion was confirmed by plasmid DNA isolation and gel electrophoresis. Thus, as predicted, the IncP-1 loci chosen were sufficiently generic to work on plasmids from both $\alpha$ and $\beta$ subgroups.

\section{Conclusions}

The work described in this paper demonstrates the effectiveness in plasmid curing of newly constructed plasmids that incorporate genetic loci that not only interfere with replication but also, crucially, neutralize the action of PSK systems encoded by the target plasmid. To allow the subsequent selection of plasmid-free segregants the pCURE system uses an unstable vector that carries the counterselectable sacB gene.

The power of our approach is demonstrated particularly with the complex IncF plasmids, which often carry multiple replicons and stability determinants and are well known for being very difficult to cure $(12,44)$. By contrast, the pCURE approach is highly effectively and does not appear to involve loss of viability of the bacteria due to the displacement at any stage. The recent report of coupling the new $\mathrm{Ti}$ plasmid PSK system to the previously described replication-based displacement vector $(9,45)$ appears to corroborate this as an effective approach.

\section{Acknowledgments}

This work was partly funded by Biotechnology and Biological Sciences Research Council (BBSRC) Exgen grant no. EGA16107, and two grants from the Mercia Spinner fund. A.S.H. was supported by a project grant from The Wellcome Trust (grant no. 063083). The DNA sequencing was carried out in the University of Birmingham Functional Genomics Laboratory funded by BBSRC grant no. JI6/F13209.

\section{Competing interests}

The plasmids described in this paper are the subject of Patent No. P560304PC, owned by the University of Birmingham, and currently licensed to Plasgene, of which C.M.T. is Managing Director. A.S.H is a previous employee of Plasgene.

\section{References}

1. Top, E., Y. Moenne-Loccoz, T. Pembroke, and C.M. Thomas. 2000. Phenotypic traits conferred by plasmids, pp. 249-285. In C.M. Thomas (Ed.), The Horizontal Gene Pool: Bacterial plasmids and gene spread. Harwood Academic Publishers, Amsterdam.

2.Stanisich, V.A. 1984. Identification and analysis of plasmids at the genetic level, pp. 5-32. In P.M. Bennett and J. Grinsted (Eds.), Plasmid Technology. Academic Press, London.

3. Novick, R.P. 1987. Plasmid Incompatibility. Microbiol. Rev. 51:381-395.

4. Timmis, K., F. Cabello, and S.N. Cohen. 1974. Utilisation of two distinct modes of replication by a hybrid plasmid constructed in vitro from separate replicons. Proc. Natl. Acad. Sci. USA 71:4556-4560.

5. Couturier, M., F. Bex, P.L. Berquist, and W. Maas. 1988. Identification and classification of bacterial plasmids. Microbiol. Rev. 52:375395.

6.Gerdes, K., S. Ayora, I. Canosa, P. Ceglowski, R. Diaz-Orejas, T. Franch, A.P. Gultyaev, R. Bugge Jensen, et al. 2000. Plasmid maintenance systems, pp. 49-85. In C.M. Thomas (Ed.), The Horizontal Gene Pool: Bacterial Plasmids and Gene Spread. Harwoord Academic Press, Amsterdam.

7. Bernard, P. and M. Couturier. 1992. Cell killing by the $\mathrm{F}$ plasmid $\mathrm{CcdB}$ protein involves poisoning of DNA-topoisomerase II complexes. J. Mol. Biol. 226:735-745.

8.Jiang, Y., J. Pogliano, D.R. Helinski, and I. Konieczny. 2002. ParE toxin encoded by the broad-host-range plasmid RK2 is an inhibitor of Escherichia coli gyrase. Mol. Microbiol. 44:971-979.

9. Yamamoto, S., K. Kiyokawa, K. Tanaka, K. Moriguchi, and K. Suzuki. 2009. Novel toxinantitoxin system composed of serine protease and AAA-ATPase homologues determines the high level of stability and incompatibility of the tumor-inducing plasmid pTiC58. J. Bacteriol. 191:4656-4666.

10. Burland, V., Y. Shao, N.T. Perna, G. Plunkett, H.J. Sofia, and F.R. Blattner. 1998. The complete DNA sequence and analysis of the large virulence plasmid of Escherichia coli O157: H7. Nucleic Acids Res. 26:41964204 .

11.Makino, K., K. Ishii, T. Yasunaga, M. Hattori, K. Yokoyama, C.H. Yutsudo, T. Kubota, Y. Yamaichi, et al. 1998. Complete nucleotide sequences of $93-\mathrm{kb}$ and $3.3-\mathrm{kb}$ plasmids of an enterohemorrhagic Escherichia coli O157:H7 derived from Sakai Outbreak. DNA Res. 5:1-9.

12. Tatsuno, I., M. Horie, H. Abe, T. Miki, K. Makino, H. Shinagawa, H. Taguchi, S. Kamiya, et al. 2001. toxB gene on pO157 of enterohemorrhagic Escherichia coli O157: H7 is required for full epithelial cell adherence phenotype. Infect. Immun. 69:6660-6669.

13. Pansegrau, W., E. Lanka, P.T. Barth, D.H. Figurski, D.G. Guiney, D. Haas, D.R. Helinski, H. Schwab, et al. 1994. Complete nucleotide sequence of Birmingham IncPalpha plasmids - compilation and comparative analysis. J. Mol. Biol. 239:623-663.

14. Thorsted, P.B., D.P. Macartney, P. Akhtar, A.S. Haines, N. Ali, P. Davidson, T. Stafford, M.J. Pocklington, et al. 1998.
Complete sequence of the IncP beta plasmid R751: implications for evolution and organisation of the IncP. backbone. J. Mol. Biol. 282:969-990.

15. Hanahan, D. 1983. Studies on transformation of Escherichia coli with plasmids. J. Mol. Biol. 166:557-580.

16. Simon, R., U. Priefer, and A. Puhler. 1983. A broad host range mobilization system for in vivo genetic-engineering-transposon mutagenesis in Gram-negative bacteria. Bio/ Technology 1:784-791.

17. Murray, N.E., W.J. Brammar, and K. Murray. 1977. Lambdoid phages That simplify recovery of in vitro recombinants. Mol. Gen. Genet. 150:53-61.

18. Yanisch-Perron, C., J. Vieira, and J. Messing. 1985. Improved M13 phage cloning vectors and host strains - nucleotide-sequences of the M13mp18 and pUC19 vectors. Gene 33:103-119.

19. Birnboim, H.C. and J. Doly. 1979. A rapid alkaline extraction procedure for screening recombinant plasmid DNA. Nucleic Acids Res. 7:1513-1523.

20.Sambrook, J., E.F. Fritsch, and T. Maniatis. 1989. Molecular Cloning: a Laboratory Manual. Cold Spring Harbor Laboratory, Cold Spring Harbor, New York.

21.Sanger, F., S. Nicklen, and A.R. Coulson. 1977. DNA sequencing with chain terminating inhibitors. Proc. Natl. Acad. Sci. USA 74:5463-5467.

22.Mullis, K., F. Faloona, S. Scharf, R. Saiki, G. Horn, and H. Erhlich. 1986. Specific enzymatic amplification of DNA in vitro: the polymerase chain reaction. Cold Spring Harb. Symp. Quant. Biol. 51:263-273.

23.El-Sayed, A.K., J. Hothersall, S.M. Cooper, E. Stephens, T.J. Simpson, and C.M. Thomas. 2003. Characterization of the mupirocin biosynthesis gene cluster from Pseudomonas fuorescens NCIMB 10586. Chem. Biol. 10:419-430.

24. West, S.E., H.P. Schweizer, C. Dall, A.K. Sample, and L.J. Runyen-Janecky. 1994. Construction of improved Escherichia-Pseudomonas shuttle vectors derived from pUC18/19 and sequence of the region required for their replication in Pseudomonas aeruginosa. Gene 148:81-86.

25.Ried, J.L. and A. Collmer. 1987. An $n p t I-s a c B-s a c R$ cartridge for constructing directed, unmarked mutations in gramnegative bacteria by marker exchange-eviction mutagenesis. Gene 57:239-246.

26. Womble, D.D. and R.H. Rownd. 1988. Genetic and physical map of plasmid NR1: comparison with other IncFII antibiotic resistance plasmids. Microbiol. Rev. 52:433451.

27.Saul, D., A.J. Spiers, J. McAnulty, M.G. Gibbs, P.L. Bergquist, and D.F. Hill. 1989. Nucleotide-sequence and replication characteristics of RepFIB, a basic replicon of IncF plasmids. J. Bacteriol. 171:2697-2707.

28.Jaffe, A., T. Ogura, and S. Hiraga. 1985. Effects of the Ccd function of the F-Plasmid on bacterial-growth. J. Bacteriol. 163:841-849.

29. Gerdes, K., P.B. Rasmussen, and S. Molin. 1986. Unique type of plasmid maintenance function - postsegregational killing of plasmid-free cells. Proc. Natl. Acad. Sci. USA 83:3116-3120. 
30.Gerdes, K., T. Thisted, and J. Martinussen. 1990. Mechanism of post-segregational killing by the Hok Sok system of plasmid-R1-Sok antisense RNA regulates formation of a Hok messenger-RNA species correlated with killing of plasmid-free cells. Mol. Microbiol. 4:1807-1818.

31. Light, J. and S. Molin. 1982. The sites of action of the two copy number control functions of plasmid R1. Mol. Gen. Genet. 187:486-493.

32.Uga, H., F. Matsunaga, and C. Wada. 1999. Regulation of DNA replication by iterons: an interaction between the ori2 and inc $C$ regions mediated by RepE-bound iterons inhibits DNA replication of mini-F plasmid in Escherichia coli. EMBO J. 18:3856-3867.

33.Zienkiewicz, M., I. Kern-Zdanowicz, M. Golebiewski, J. Zylinska, P. Mieczkowski, M. Gniadkowski, J. Bardowski, and P. Ceglowski. 2007. Mosaic structure of p1658/97, a 125-kilobase plasmid harboring an active amplicon with the extended-spectrum beta-lactamase gene bla(SHV-5). Antimicrob. Agents Chemother. 51:1164-1171.

34.Haneda, T., N. Okada, N. Nakazawa, T. Kawakami, and H. Danbara. 2001. Complete DNA sequence and comparative analysis of the 50-kilobase virulence plasmid of Salmonella enterica serovar Choleraesuis. Infect. Immun. 69:2612-2620.

35. Rokeach, L.A., L. Sogaardandersen, and S. Molin. 1985. 2 Functions of the
E-protein are key elements in the plasmid-F replication control-system. J. Bacteriol. 164:1262-1270.

36. Thomas, C.M., D.M. Stalker, and D.R. Helinski. 1981. Replication and Incompatibility properties of segments of the origin region of replication of the broad host range plasmid Rk2. Mol. Gen. Genet. 181:1-7.

37. Blasina, A., B.L. Kittell, A.E. Toukdarian, and D.R. Helinski. 1996. Copy-up mutants of the plasmid RK2 replication initiation protein are defective in coupling RK2 replication origins. Proc. Natl. Acad. Sci. USA 93:3559-3564.

38. Roberts, R.C. and D.R. Helinski. 1992. Definition of a minimal plasmid stabilization system from the broad-host-range plasmid RK2. J. Bacteriol. 174:8119-8132.

39. Bechhofer, D.H. and D.H. Figurski. 1983. Map location and nucleotide sequence of KorA, a key regulatory gene of promiscuous plasmid RK2. Nucleic Acids Res. 11:74537469.

40.Motallebi-Veshareh, M., D.A. Rouch, and C.M. Thomas. 1990. A family of ATPases involved in active partitioning of diverse bacterial plasmids. Mol. Microbiol. 4:14551463.

41.Shinger, V. and C.M. Thomas. 1984 . Transcription in the $\operatorname{trf} A$ region of broad hostrange plasmid RK2 is regulated by $\operatorname{trf} B$ and korB. Mol. Gen. Genet. 195:523-529.
42.Meyer, R. and M. Hinds. 1982 Multiple mechanisms for expression of incompatibility by broad host range plasmid RK2 J. Bacteriol. 152:1078-1090.

43. Thomas, C.M., R. Meyer, and D.R. Helinski. 1980. Regions of broad-host-range plasmid RK2 which are essential for replication and maintenance. J. Bacteriol. 141:213222.

44.Johnson, T.J. and L.K. Nolan. 2009. Pathogenomics of the virulence plasmids of Escherichia coli. Microbiol. Mol. Biol. Rev. 73:750-774.

45. Uraji, M., K. Suzuki, and K. Yoshida. 2002. A novel plasmids curing method using incompatibility of plant pathogenic $\mathrm{T}$ plasmid in Agrobacterium tumefaciens. Genes Genet. Syst. 77:1-9.

Received 30 November 2009; accepted 22 January 2010

Address correspondence to Christopher M. Thomas, School of Biosciences, University of Birmingham, Edgbaston, Birmingham B15 2TT, UK.e-mail: c.m.thomas@bham.ac.uk

\section{BREAKTHROUGH IN RNA ISOLATION The single step method without phase separation}

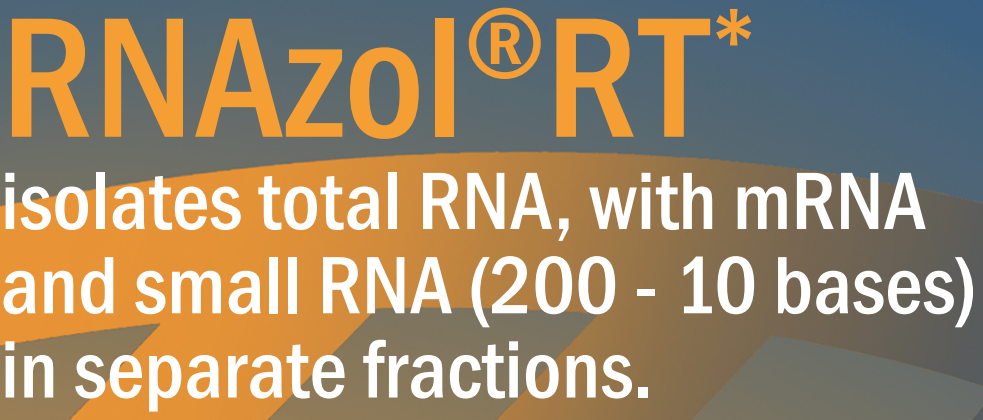

- Higher RNA yield and quality than with previous single-step reagents.

- No chloroform-induced phase separation. Just add water.

- RNA is ready for RT-PCR, microarrays, poly A+ selection, northern blotting and RNase protection.

- No DNase treatment necessary.

- No need for a refrigerated centrifuge. All steps performed at room temperature.

MOLECULAR RESEARCH CENTER, INC. 5645 Montgomery Road, Cincinnati, Ohio 45212
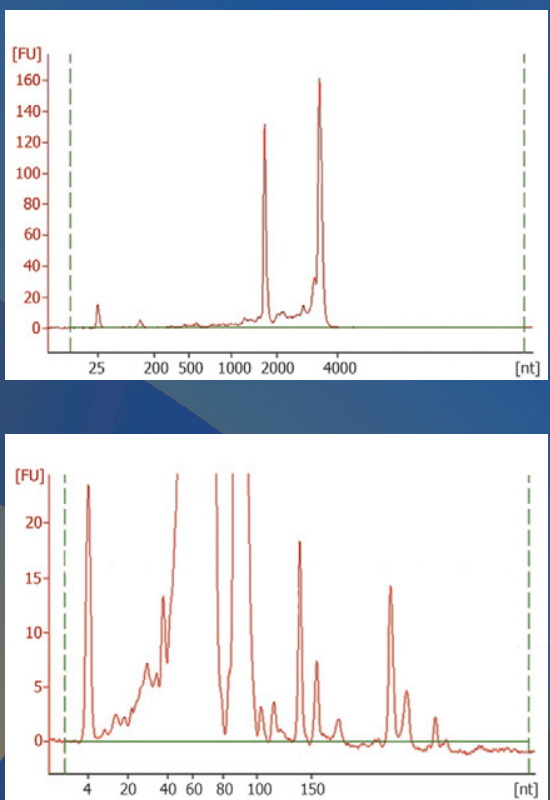

www.mrcgene.com Phone: (888) 841-0900 